\title{
Multidose drug dispensing and discrepancies between medication records
}

\author{
Liv Johanne Wekre, ${ }^{1,2,3}$ Olav Spigset, ${ }^{4,5}$ Olav Sletvold, ${ }^{6,7}$ Janne Kutschera Sund, ${ }^{2}$ \\ Anders Grimsmo ${ }^{1,3}$
}

${ }^{1}$ Department of Community Medicine and General Practice, Norwegian University of Science and Technology (NTNU) Trondheim, Norway ${ }^{2}$ Central Norway Hospital Pharmacy Trust, Trondheim, Norway

${ }^{3}$ Norwegian EHR Research Centre, Norwegian University of Science and Technology (NTNU), Trondheim, Norway ${ }^{4}$ Department of Laboratory Medicine, Children's and Women's Health, Norwegian University of Science and Technology (NTNU), Trondheim, Norway

${ }^{5}$ Department of Clinical Pharmacology, St Olav University Hospital, Trondheim, Norway

${ }^{6}$ Department of Neuroscience, Norwegian University of Science and Technology (NTNU),

Trondheim, Norway

${ }^{7}$ Section of Geriatrics, Department of Internal Medicine, St Olav University Hospital, Trondheim, Norway

\section{Correspondence to}

Mrs Liv Johanne Wekre Department of Community Medicine and General Practice, Norwegian University of Science and Technology (NTNU), MTFS, Trondheim, Norway:

liv.j.wekre@ntnu.no

Accepted 24 February 2010 Published Online First

4 August 2010

\section{ABSTRACT \\ Background The objective of this study was to investigate whether implementation of multidose drug dispensing (MDD) for elderly outpatients is associated with a change in the number of discrepancies in the medication record at the general practitioners (GPs) and at the community home-care services.}

Methods A controlled follow-up study with paired design of patients' medication records was performed during implementation of MDD. Medication records from the home care units and from the GPs were reviewed, and the discrepancies were noted. The discrepancies were rated into four classes based upon the potential harm, and a risk score system was applied, giving the potentially most harmful discrepancies the highest score. Results Medication records from 59 patients with a mean age of 80 years were included. The number of discrepancies was reduced from 203 to $133(p<0.001)$, and the total risk score decreased from 308 to 181 $(p<0.001)$ after the implementation of MDD. For both drugs subject to MDD and drugs not suitable for MDD, the reductions in discrepancies were significant (39\% and $31 \%$ reduction respectively).

Conclusions Calculated health risk due to discrepancies between the medication records from the home-care service and from the GPs decreased during the time of implementation of the MDD system. It seems likely that most of the positive effect was caused by the change in routines and enhanced focus on the medication process rather than by MDD per se.

\section{INTRODUCTION}

Incorrect use and incorrect handling of drugs is a major problem both in specialist care and in primary care. ${ }^{12}$ Even when limited to primary care, the number of adverse drug events has been seriously high in international studies. ${ }^{3-5}$ Both GPs and home-care services sense this problem and have expressed dissatisfaction with the collaboration regarding the medication of shared patients. ${ }^{6}$

In 1999, the Norwegian Board of Health initiated work on a plan of action aimed towards safer use of medicines. The focus was especially directed towards primary care services. " A number of actions was suggested, one of which was the use of $\mathrm{MDD}$ in nursing homes and home-care services. MDD implies that patients receive their drugs machine-dispensed into one unit for each dose occasion, packed into disposable bags. The dose unit bags are labelled with patient data, drug contents data and time for intake. ${ }^{8-10}$

The number of MDD users is growing. In 2002, there were about 3000 MDD users in Norway; in
2006, the number had grown to 16000 and in 2009 to approximately 35000 . Eighty per cent of the MDD users receive home-care service. There is an estimated potential of including a total of 200000 patients from the primary care in Norway into the MDD system. ${ }^{11} 12 \mathrm{MDD}$ is expected to reduce medication errors, increase drug adherence and decrease waste of unused drugs. $^{813-15}$ Still, more research is needed to document the effects of the system. ${ }^{12}$

Care of patients in their homes requires collaboration between GPs and home care providers who generally do not physically work together. Furthermore, GPs and home-care services maintain separate medication records for patients they have in common. In the MDD system, the pharmacy sets up one medication record for each MDD user, which is shared electronically with the company responsible for packing the multidose drugs. This record gives the pharmacist a complete overview of the patients' drugs. It includes both drugs processed by the MDD system and drugs dispensed manually as before.

The aim of this study was to investigate whether the implementation of MDD for elderly outpatients was associated with a change in inconsistencies when comparing medication records from the GPs and the home-care services. We wanted to study both the number of discrepancies and the potential of the discrepancies to cause harm to the patients. To our knowledge, a controlled before-after study such as this has not been conducted before

\section{METHODS}

Ten home care units in the city of Trondheim, Norway, each recruited up to 15 patients for participation, selecting the first 15 patients on an alphabetical list. The nurses responsible for the implementation of $\mathrm{MDD}$ in the units performed the selection and obtained informed consent.

Medication records from the GPs and from the home-care services were collected half a year before and 1 year after the implementation of MDD. After the implementation, medication records from the pharmacies responsible for delivering the $\mathrm{MD}$ packages were provided as well. The study ran from May 2006 to January 2008.

The primary outcome was discrepancies between the patients' medication records at the GPs and at the home-care services, and the number of drugs in the GPs' medication records. The discrepancies were rated for their potential to cause patient harm by a team consisting of two pharmacists, a GP, a clinical pharmacologist and a geriatrician. Each member of the team made an individual assessment 
Table 1 Classification of discrepancies according to potential harm

Class $1 \quad$ Discrepancies unlikely to cause patient discomfort or clinical deterioration. An example would be prescription discrepancies in timing of the dose where this was considered unimportant, or discrepancies involving drugs considered not potent (eg, some vitamins).

Class 2 Discrepancies with the potential to cause moderate discomfort or clinical deterioration. An example would be a patient given a hypnotic drug every night by the home-care services, even though it was prescribed as required in the GP's record.

Class 3 Discrepancies with the potential to result in severe discomfort or clinical deterioration. An example would be when warfarin was missing in one of the two records.

Class 0 It could not be decided with certainty whether the discrepancy was a true discrepancy or not. An example is lack of information on vitamin $B_{12}$ injections in the home-care service records. This could result in a patient not receiving the injection (an error); alternatively could the injection each time be given at the GP's office (no error). In the latter case, the information was not needed at the home-care services since they were not responsible for the administration of the drug.

before the joint evaluation. In cases of disagreement about the inconsistencies, the issue was resolved by discussion. Consensus was reached in all cases. The team members were blinded with regard to whether the records were collected before or after MDD was implemented.

Assessment was done by a validated method, ${ }^{16-18}$ and discrepancies were rated into one of three classes according to whether they had minimal, moderate or severe potential to harm. In addition, we included a fourth class of non-classifiable discrepancies (table 1).

Discrepancies caused both by discordant prescriptions and by missing information in the medication records were registered. $^{8} 16^{19-21}$ Two approaches were used to study whether there were any significant changes before and after the implementation of MDD:

1. Comparing the sum of risk scores belonging to the pair of medication records from the GP and from the home-care services, before and after implementation of MDD. The sum of risk scores was calculated by giving a class 1 discrepancy 1 point, a class 2 discrepancy 2 points and a class 3 discrepancy 3 points. Class 0 discrepancies gave no points.

2. Comparing the number of high-risk medication records before and after implementation of MDD. High-risk medication records were defined by the following criteria:

a. Records where the sum of risk-scores was 6 or higher.

b. Records containing one or more class 3 discrepancies.

The drugs were divided into three groups: (1) drugs subject to MDD, (2) drugs not suitable for MDD and (3) drugs prescribed to be used as required. By doing this, we were able to set up an internal control. ${ }^{22}$ We could study whether changes in the number of discrepancies were present among drugs subject to MDD only or whether the changes observed were independent of the MDD per se.

Analyses were completed using Microsoft Office Excel 2003 (Microsoft, Seattle, Washington) and SPSS (version 16; SPSS, Chicago, Illinois) for Windows. The statistical analyses used were the Student $t$ test for paired samples for continuous data and the McNemar test for paired nominal data. $p$ Values $<0.05$ were considered statistically significant.

\section{RESULTS}

In total, 136 patients were included after the first collection of medication records. However, only 59 patients (43\%) remained in the final material. The 77 drop-outs were as follows: 43 patients were not considered suitable for using MDD or did not receive home care when $\mathrm{MDD}$ was implemented, 20 patients had had MDD for a period of time but quit before the last collection of medication records, and 14 patients did receive MDD at the time of evaluation, but not all medication records were available (eight records missing from the GPs, three records missing from the home-care services and three records missing from the pharmacies). The patients had a mean age of 80 years at study start, ranging from 52 to 92 years. Forty-six (78\%) of the patients were female. For comparison, the dropout patients had a mean age of 78 years, ranging from 34 to 98 years, and $56 \%$ were female.

The total number of drugs listed in the 59 medical records from the GPs was 386 before the implementation of MDD and 424 after the implementation $(p=0.016)$. Before the implementation, there were 47 medication records $(80 \%)$ with discrepancies, as compared with 45 records (76\%) with discrepancies after the implementation $(p=0.774)$.

In total, there was a $34 \%$ reduction in the number of discrepancies after implementation of MDD $(p<0.001)$. The risk classification of the discrepancies is presented in table 2. For drugs subject to $\mathrm{MDD}$, the reduction in the number of discrepancies was 39\%, whereas for drugs not suitable for MDD (eg, injections, mixtures, eye-drops) and drugs to be used as required, the reduction was $31 \%$. Table 3 shows the number of discrepancies for these three groups.

The various types of discrepancies are presented in table 4. The most frequent type of discrepancy both before and after implementation of MDD was that a prescription in the home-care services record was missing in the GP's record. The second most frequent discrepancy was that a prescription in the GP's record was lacking in the home-care services record.

For all the 59 pairs of medication records, there was a total risk score of 308 before the implementation and 181 after the implementation of MDD $(p<0.001)$. There was also a significant

Table 2 Risk classification of discrepancies between the medication records from the general practitioners and from the home-care services before and after the implementation of multidose drug dispensing

\begin{tabular}{|c|c|c|c|c|}
\hline Potential harm* & $\begin{array}{l}\text { No of discrepancies before } \\
\text { implementation, } \mathrm{N} \dagger=386\end{array}$ & $\begin{array}{l}\text { No of discrepancies after } \\
\text { implementation, } \mathrm{N} \dagger=424\end{array}$ & $\begin{array}{l}\text { Absolute reduction in the percentage } \\
\text { of discrepancies }(95 \% \mathrm{CI})\end{array}$ & $\begin{array}{l}p \\
\text { Value }\end{array}$ \\
\hline Not classified (class 0 ) & $12(3 \%)$ & $12(3 \%)$ & $0.29 \%(-1.15 \%$ to $1.73 \%)$ & 0.690 \\
\hline Unlikely to cause discomfort (class 1 ) & $84(22 \%)$ & $66(15 \%)$ & $6.66 \%(0.67 \%$ to $12.7 \%)$ & 0.030 \\
\hline $\begin{array}{l}\text { Potential to cause severe discomfort } \\
\text { (class 3) }\end{array}$ & $10(3 \%)$ & $5(1 \%)$ & $1.54 \%(-1.87 \%$ to $4.95 \%)$ & 0.369 \\
\hline
\end{tabular}

*See text for a detailed explanation of the risk classification procedure.

†Number of prescriptions. 
Table 3 Number of discrepancies between the medication records from the general practitioner and from the home-care services before and after the implementation of multidose drug dispensing, classified on the basis of whether the drugs were dispensed in a multidose package or not

\begin{tabular}{|c|c|c|c|c|}
\hline & $\begin{array}{l}\text { No of discrepancies before } \\
\text { implementation, } N \dagger=386\end{array}$ & $\begin{array}{l}\text { No of discrepancies after } \\
\text { implementation, } \mathrm{N} \dagger=424\end{array}$ & $\begin{array}{l}\text { Absolute reduction in the percentage } \\
\text { of discrepancies }(95 \% \mathrm{Cl})\end{array}$ & p Value \\
\hline Multidose dispensable drugs & $82(21 \%)$ & $50(12 \%)$ & $10.2 \%(3.1 \%$ to $17.3 \%)$ & 0.006 \\
\hline $\begin{array}{l}\text { Drugs not suitable for multidose } \\
\text { dispensing }\end{array}$ & $51(13 \%)$ & $34(8 \%)$ & $5.0 \%(1.2 \%$ to $8.7 \%)$ & 0.010 \\
\hline Drugs to be used as required & $70(18 \%)$ & $49(12 \%)$ & $6.0 \%(0.42 \%$ to $11.6 \%)$ & 0.036 \\
\hline Total & $203(53 \%)$ & $133(31 \%)$ & $21.0 \%(11.8 \%$ to $30.2 \%)$ & $<0.001$ \\
\hline
\end{tabular}

†Number of prescriptions.

reduction in the number of high-risk medication records during the implementation of MDD $(\mathrm{p}<0.02)$ (table 5$)$.

When the medication records at the GPs and at the home-care services were compared with the records from the pharmacies after implementation of MDD, we found 151 discrepancies. There were discrepancies between the pharmacy record and the GP record in 49 drug prescriptions and between the pharmacy record and the home-care services record in 133 drug prescriptions. In 31 drug prescriptions the pharmacy record neither agreed with the GP record nor the home-care service record.

\section{DISCUSSION}

Results from this study show a better agreement between the information in the medication records from the GPs and at the home-care services after the implementation of MDD compared with before the implementation. This improvement caused a drop in estimated health risks due to discrepancies in spite of a registered increase in the number of drugs in the medication records.

A significant reduction in the number of discrepancies was seen not only for the drugs subject to MDD, but also for the drugs not suitable for MDD (table 3 ). This finding supports the assumption that changes in routines constitute a central factor in the improvement and that the improvement is not necessarily due to the MDD alone. The improvement could be attributed to the implementation process itself, and to the work done by the different participants. The amount of allocated resources, the mandate from the city council to the implementation team and other routines adopted could also be of importance.

In previous Norwegian studies, it has been shown that up to $90 \%$ of the patients had one or more discrepancies in their medication records at the home-care services compared with the medication record at the GP, ${ }^{20}{ }^{21}$ whereas we found $80 \%$ before the implementation of MDD. A study from 2004 showed that there were discrepancies in records belonging to patients receiving $\mathrm{MDD}$ as well. ${ }^{23}$ Regarding the GPs' and home-care services' records, discrepancies were disclosed in $52 \%$ of the patients in that study, ${ }^{23}$ whereas we found that $76 \%$ of the multidose patients had at least one discrepancy. A small study from 2001 indicated that MDD causes no better agreement in medication records than manual dispensing of drugs. ${ }^{8}$ This may again indicate that the established routines in the home-care services, at the GPs and at the pharmacies, together with the information work accomplished during the implementation of $\mathrm{MDD}$, are important factors in order to achieve improved drug safety in the MDD system.

The home-care services in Trondheim have used electronic health records (EHRs) since 1996, and its medication module regularly since 1998. This should be accounted for when comparing the results with the findings from other studies ${ }^{24}$ since EHRs are not yet common everywhere. ${ }^{24}$ All medication records from the community home-care services that we used in the present study were printed out from the EHR.

Ninety-eight per cent of GPs in Norway have EHRs, ${ }^{25}$ but even though all of them use the EHR when printing out single prescriptions, the updating of the patient medication record has not been carried out systematically. Before the implementation of $\mathrm{MDD}, 10$ of the included medication records from the GPs were not printed out from the EHR medication module, as compared with only one after the implementation. The better routines among GPs in updating the medication records probably contributed to the reduction in discrepancies that we found.

We found a reduced number of discrepancies and a decrease in estimated health risks due to discrepancies in the medication records after the implementation of MDD. Studies show, however, that a reduction in prescribing errors will not necessarily be followed by a decrease in adverse drug events. ${ }^{26}$ Handling of the medication after removing it from the packaging may still contribute to a high error frequency. ${ }^{27} \mathrm{On}$

Table 4 Type of discrepancies between the medication records from the general practitioner and from the home-care services before and after the implementation of multidose drug dispensing

\begin{tabular}{lcc}
\hline Type of discrepancy & $\begin{array}{l}\text { No of discrepancies before } \\
\text { implementation, } \mathbf{N}=\mathbf{2 0 3}\end{array}$ & $\begin{array}{c}\text { No of discrepancies after } \\
\text { implementation, } \mathbf{N}=\mathbf{1 3 3}\end{array}$ \\
\hline Prescription lacking in the record from the general practitioner & $83(41 \%)$ & $49(37 \%)$ \\
Prescription lacking in the record from the home-care services & $0(34 \%)$ & $29(22 \%)$ \\
Different dosage & $30(15 \%)$ & $32(24 \%)$ \\
Fixed prescription versus prescribed as required & $7(4 \%)$ & $4(3 \%)$ \\
Different dose frequency* & $3(1 \%)$ & $6(4 \%)$ \\
Missing informationt & $4(2 \%)$ & $7(5 \%)$ \\
Others & $6(3 \%)$ & $6(4 \%)$ \\
Total & $203(100 \%)$ & $133(100 \%)$ \\
\hline
\end{tabular}

*Different dose frequency but the same total daily dose, for example $50 \mathrm{mg} \times 2$ versus $100 \mathrm{mg} \times 1$.

†Missing information about type of formulation or drug dose in the prescription. 
Table 5 Number of high-risk medication records before and after the implementation of multidose drug dispensing $(\mathrm{p}<0.02)$

\begin{tabular}{lccc}
\hline & \multicolumn{3}{l}{$\begin{array}{l}\text { High-risk medication record } \\
\text { after implementation }\end{array}$} \\
\cline { 2 - 4 } $\begin{array}{l}\text { High-risk medication record before } \\
\text { implementation }\end{array}$ & 8 & 19 & 27 \\
\hline Yes & 6 & 26 & 32 \\
No & 14 & 45 & 59 \\
\hline Total & & No & Total \\
\hline
\end{tabular}

the other hand, the MDD system may reduce the number of prescribers, which is an independent risk factor. ${ }^{28}$

\section{Limitations of the study}

The dropout rate was large, $57 \%$. Since the study population was old, and not all patients are suited for MDD, this was expected. Twenty patients $(15 \%)$ in the dropout group had received $\mathrm{MDD}$ in a period of time before the follow-up. We cannot exclude with certainty that some of them may have died from reasons connected to the implementation of MDD, but we do not have any information that this did happen.

Use of multiple statistical testing can inflate the type I error rate, so some of the statistically significant findings could be spurious, and the small sample size means that some possibly important differences could have been missed.

We considered the selection of patients from an alphabetical list to be convenient. As the selection was done by the last names of the patients, the risk of drawing family members could be increased. However, the patients were recruited from 10 different home care units, and we do not consider that this procedure has introduced any relevant bias.

The implementation process in Trondheim precluded the possibility of including a control of patients not subject to MDD from the same municipality. Including an external control group would involve a different organisation prone to be influenced by other factors in the study period. Instead, we made an internal control by comparing drugs subject to $\mathrm{MDD}$ and drugs not suitable for MDD. Changes in the latter group should not be caused by the introduction of the MDD system per se, but if such changes occurred, they should be due to other elements common to both groups.

Access to clinical data could have made the classification of the discrepancies more reliable. ${ }^{1718}$ However, the classification used in this study has also been used by others based on drug information data alone ${ }^{16}$ and is validated for use in settings like the present one.

The GPs and the home care units were informed about the study, thus giving them the opportunity to scrutinise the lists before they were forwarded to the study investigators. Before the implementation of the MDD system, the home care personnel collected the medication records from the GPs and handed them over to the study investigators together with their own medication records. This procedure gave them an opportunity to change their own medication records, thereby omitting discrepancies. After the implementation of $\mathrm{MDD}$, the study investigators contacted the GPs and the home-care services separately. The home-care services and the GPs could then not compare their records directly, but they had, at least in theory, the chance to check their records against the records they receive from the pharmacy when changes are made in the multidose packages. However, since the home care units were asked for several (until 15) medication records, a double check would be timeconsuming. Hence, we consider such a scenario unlikely.

Finally, any generalisation of findings in a study from one single administration and organisation should be done with caution, and this is also the case for the findings in this study.
Acknowledgements We thank the GPs and the personnel at the home-care services and at the pharmacies for their time spent on the study. Thanks to Helge Garåsen and members of the council implementation group for the support given. We also acknowledge E Baukol Risheim, for her work with the study during her Master's thesis, and Pål Romundstad, for help with the statistics.

Funding Liaison Committee between the Central Norway Regional Health Authority (RHA) and the Norwegian University of Science and Technology (NTNU).

\section{Competing interests None.}

Patient consent Obtained.

Ethics approval Ethics approval was provided by the Regional Committee for Medical Research Ethics (REK) and the Norwegian Data Inspectorate (NSD).

Provenance and peer review Not commissioned; externally peer reviewed.

\section{REFERENCES}

1. Anon. Handlingsplan for sikrere legemiddelbruk non-en. Oslo: Statens helsetilsyn, 2000.

2. Harg $\mathbf{P}$, Lislevand $\mathrm{H}$, Buajordet $\mathrm{I}$, et al. Adverse drug reaction reporting and drug monitoring. Tidsskr Nor Laegeforen 2003;123:331-2.

3. Friedman AL, Geoghegan SR, Sowers NM, et al. Medication errors in the outpatient setting: classification and root cause analysis. Arch Surg 2007;142:278-83; discussion 84

4. Gandhi TK, Weingart SN, Borus J, et al. Adverse drug events in ambulatory care. N Engl J Med 2003;348:1556-64.

5. Weingart SN, Gandhi TK, Seger AC, et al. Patient-reported medication symptoms in primary care. Arch Intern Med 2005;165:234-40.

6. Bakken $\mathbf{K}$, Larsen $\mathrm{E}$, Lindberg PC, et al. Insufficient communication and information regarding patient medication in the primary healthcare. Tidsskr Nor Laegeforen 2007:127:1766-9.

7. Anon. Sikrere legemiddelhåndtering i pleie- og omsorgstjenester non-en. Oslo: Statens helsetilsyn, 2002.

8. Bakken T, Straand J. Improved medicine lists with multi-dose packaging? Tidsskr Nor Laegeforen 2003;123:3595-7.

9. Bergman A, Olsson J, Carlsten A, et al. Evaluation of the quality of drug therapy among elderly patients in nursing homes. Scand J Prim Health Care 2007;25:9-14.

10. Johnell K, Fastbom J. Multi-dose drug dispensing and inappropriate drug use a nationwide register-based study of over 700,000 elderly. Scand J Prim Health Care 2008:26:86-91.

11. St.meld.nr.18. Rett kurs mot riktigere legemiddelbruk non-en. Oslo: Det kongelige helse- og omsorgsdepartement, 2005

12. Anon. Multidosepakking av legemidler En samfunnsøkonomisk vurdering av tiltak non-en. Oslo: Price Waterhouse Coopers, 2007

13. Gombos A. Multi-dose packaging is a good system. Tidsskr Nor Laegeforen 2004; 124:1144.

14. Åkerlund $\mathbf{M}$, Vissgården A. ApoDos-The National Corporation of Swedish Pharmacies' multi-dose dispensed medicines. Stockholm: Läkemedelsboken 2009/ 2010: Apoteket AB (National Corporation of Swedish Pharmacies), 2007.

15. Danish Medicines Agency. Dose dispensing. 2006 Copenhagen. http://www. dkma.dk/db/filarkiv/6080/Dose\%20dispensing.pdf (accessed 3 Oct 2006).

16. Arora V, Kao J, Lovinger D, et al. Medication discrepancies in resident sign-outs and their potential to harm. J Gen Intern Med 2007:22:1751-5.

17. Cornish PL, Knowles SR, Marchesano R, et al. Unintended medication discrepancies at the time of hospital admission. Arch Intern Med 2005;165:424-9.

18. Nickerson A, MacKinnon NJ, Roberts N, et al. Drug-therapy problems, inconsistencies and omissions identified during a medication reconciliation and seamless care service. Healthc 0 2005;8 Spec No:65-72.

19. Barat I, Andreasen F, Damsgaard EM. Drug therapy in the elderly: what doctors believe and patients actually do. Br J Clin Pharmacol 2001;51:615-22.

20. Jensen SA, Oien $T$, Jacobsen $G$, et al. Erroneous drug charts - a health hazard? Tidsskr Nor Laegeforen 2003:123:3598-9.

21. Rognstad S, Straand J. Do general practitioners know what medication community nurses give their shared patients? Tidsskr Nor Laegeforen 2004:124:810-12.

22. Wyatt JC, Wyatt SM. When and how to evaluate health information systems? Int J Med Inform 2003;69:251-9.

23. Heier KF, Olsen VK, Rognstad S, et al. Multi dose packaging for elderly outpatients: Correct medicine information and good-bye to the manuually dispensed medicines? Sykepleien Forskning 2007;3:166-70.

24. Hausen B, Tømmervaag K, Arntsen R. Bruk og utbredelse av EPJ. Aalborg: Aalborg Universitet 2005.

25. Christensen T, Faxvaag A, Loerum $\mathrm{H}$, et al. Norwegians GPs' use of electronic patient record systems. Int J Med Inform 2009:78:808-14.

26. Eslami S, Abu-Hanna A, de Keizer NF. Evaluation of outpatient computerized physician medication order entry systems: a systematic review. J Am Med Inform Assoc 2007; 14:400-6.

27. van den Bemt PM, Idzinga JC, Robertz $\mathrm{H}$, et al. Medication administration errors in nursing homes using an automated medication dispensing system. J Am Med Inform Assoc 2009;16:486-92.

28. Green JL, Hawley JN, Rask KJ. Is the number of prescribing physicians an independent risk factor for adverse drug events in an elderly outpatient population? Am J Geriatr Pharmacother 2007:5:31-9. 